IX. - São frequentes as fracturas eśpontaneas e as deformidades do esqueleto.

X. - São frequentes as metastases calcareas.

XI. - Não ha producção de metastases verdadeiras como nos blastomas e os fócos extramedullares, quando existem, constituem formações autochtonas.

XII. - Na quasi totalidade dos casos, o tecido myelomatoso neoformado é composto de um unico typo cellular.

XIII. - Esse typo cellular é quasi sempre representado pelos antecessores agranulados dos granulocytos.

XIV. - A totalidade, talvez, đos casos descriptos na litteratura, sob a denominação de plasmocytomas - não deve ser incluida nesse grupo problematico dos myelomas.

XV. - A coloração especifica de Pappenheim, para as plasmazellen de Unna-Marchalko, permitte differençar estas cellulas de outras, muito semelhantes.

XVI. - Em o nosso caso, as cellulas dos myelomas, que apresentavam, pelas colorações communs, muitos dos caracteres das cellulas plasmaticas, não tomaram o colorido especifico, sob a acção do verde de methyla-pyronina.

XVII. - A ausencia da reacção da oxydase não autoriza a exclusão diagnostica das cellulas brancas da linha myeloide, quando os outros caracteres permittam a sua identificação; Jogiç, Hirschfeld e Naegeli não obtiveram sempre a reacção do indophenol, mesmo em casos authenticos de leucemia myeloide.

XVIII. - Na doença de Rustizky-Kahler é quasi constante a presença, na urina, de um corpo albuminoso thermo-soluvel (reacção de Bence-Jones). Esta reacção foi sempre constante no nosso caso.

XIX. - Durante a evolução da doença, ha manifestações dolorosas que apparecem com intermittencias irregulares.

XX. - Manifestam-se ainda por ordem crescente de frequencia, phenomenos renaes, pulmonares, nervosos, 'digestivos, circulatorios.

XXI. -Quasi sempre, ha uma anemia progressiva, sem notavel alteração do quadro hematologico.

XXII. - Em média, a duração do processo myelomatoso é de um anno, a um anno e meio.

XXIII. - O seu prognostico é letal.

XXIV. - Até o momento actual, não ha tratamento algum para a doença de Rustizky-Kahler.

\title{
A proposito de um caso de uréthrorrhaphia circular
}

\author{
pelo Dr. Zephirino do Hmaral
}

(assistente de clinica cirurgica da Faculdade de Medicina e Cirurgia de S. Paulo)

Nas operações praticadas na urethra, é de regra applicarmos uma sonda de demóra no canal, para proteger a ferida operatoria do contacto da urina; porém na maioria dos casos, a derivação da urina pela sonda de permanencia na urethra não satisfaz o nosso "desideratum". Assim é que, não raras vezes, numa simples sutura de uma 
fistula urethro-peniana, ou na operação de hypospadias, deixamos uma sonda de demora e verificamos que no primeiro e no segundo dia a ferida operatoria se apresenta de bom aspecto; no terceiro, notamos já um pequeno corrimento sôro-purulento que se accentua no quarto dia, para no quinto ficarmos desilludidos, com o insuccesso da sutura executada com todo o capricho. Ora, se para os casos simples, a sonda de demora actua de modo tão desfavoravel para o bom exito cirurgico, numa sutura circular da urethra, a sua contra-indicação é quasi absoluta.

Quaes os inconvenientes da sonda de demora?

Em primeiro logar a sonda deve ser considerada como um corpo extranho que fica em contacto com a sutura; em segundo lugar porque não podemos mantel-a perfeitamente aseptica, pois retendo as secreções das glandulas urethraes, favorece a pullulação dos microbios normalmente existentes no canal, d'ahi a inflammação e' consequente exsudação, do segundo ou terceiro dia. em diante. Esta inflammação do canal provocada pela sonda sendo nociva para uma sutura de urethra indemne de infecção anterior, torna-se desnecessario lembrarmos que, em se tratando de individuos com passado blenorrhagico, a cicatrisação "per primam" é quasi impossivel. Não consistem só nisto os inconvenientes da sonda de permanencia; muitas vezes as mucosidades da bexiga a obliteram, ou então ella se desloca para fóra, ficando com os seus orificios obturados pelas paredes da urethra posterior e com o accumulo da urina na bexiga, esta se contrahe e impelle o liquido que se filtra entre as paredes da sonda $e$ as da urethra, vindo estagnar-se ao nivel da sutura, infiltrando, macerando e infectando os tecidos suturados, e o resultado final, será inevitavelmente a formaçã̃o de nova fistula.

Dada a hypothese feliz de se fechar a fistula, haverá ainda inconvenientes de-segunda ordem que convem mencionar: uma sutura urethral cicatrisada mesmo por primeira intenção, sob a acção irritante da sonda, dará uma cicatriz mais ampla e mais retractil que aquella que se reparou ao abrigo de qualquer inflammação, cujo resultado immediato e consecutivo é perfeito. No primeiro caso a inflammação provocada pela sonda não occasionou a desunião total da ferida, mas impediu a perfeita união da mucosa, cuja cicatrisação se fez por segunda intenção, formando nesse ponto maior quantidade de tecido fibroso, com tendencia a se estreitar, trazendo complicações futuras, para os infelizes doentés que não possam estar sempré sob as vistas do especialista. Taes foram os insuccessos da sonda de permanencia, como meio de derivação da urina, que Rochet (1906), suggeriu a feliz ideia de derivar a urina por meio de uma operação complementar a cystostomia.

Este illustre cirurgião de Lyão considera a sonda de demora como o agente mais activo de fracasso nas suturas urethraes. Marion, o 
insigne mestre do Hospital Necker, algum tempo depois, estabeleceu o seguinte principio:

Toda operação praticada na totalidade da éspessura das paredes urethraes, deve ser completada por uma fistula destinada a derivar a urina de modo absoluto. Está claro, diz este autor, que as operações endo-urethraes não entram na categoria das intervenções que reclamam derivação.

Nové-Josserand applicou este methodo de derivação na cura das hypospadias por meio do seu processo de enxertos cutaneos, com bons resultados. D'ahi por diante muitos outros cirurgiões recorreram quer á urethrostomia, quer á cystostomia, como meios de derivação da urina nas intervenções que necessitassem da reparação da urethra, seja por lesões traumaticas, seja em consequencias de resecções por estreitamentos infranqueaveis, ou fistulas.

Em Ágosto de 1913, o dr. B. Montenegro publicou nos Annaes Paulistas de Medicina e Cirurgia, um caso de uréthrorrhaphia circular com derivação vesical da urina, com pleno exito.

Dois são os modos pelos quaes podemos obter a derivação da urina: $10^{\circ}$ urethrostomia, $2 .^{\circ}$ cystostomia.

O primeiro processo consiste na abertura de uma fenda longitudinal na urethra perineal, áquem da sutura urethnal, onde se collocará uma sonda de Nelaton n. 18 de permanencia; o segundo consiste na abertura de uma pequena fistula supra-pubica (talha hypogastrica), a qual dê apenas para se deixar uma sonda de Nelaton n. 24. Em ambos os casos as sondas serão fixadas á pelle por um fio de seda, ou crina de Florença.

Qual destes dois processos o melhor? Nós damos preferencia á cystostomia por ser geralmente uma operação mais facil, e de mais prompta cicatrisação que a urethrostomia.

Casós ha em que a derivação pela talha hypogastrica é imprescindivel, como seja nos casos em que tenhamos que recorrer ao catheterismo retrogrado, para encontrar a extremidade posterior da urethra.

Feitas estas ligeiras considerações, passemos a descrever o nosso caso que deu motivo á publicação destas linhas.

Trata-se de P. A. L., brasileiro, trabalhador de lavoura, solteiro, procedente de Faxina, com 23 annos de edade; deu entrada na 1." clinica cirurgịca da Faculdade de Medicina (serviço do prof. Camargo), a 15-VIII-19.

Antecedentes hereditarios, sem importancia. Antecerlentes pessoaes, tambem carecem de importancia.

Anamnèse - Refere que foi aggredido a faca por um seu desaffecto, o qual o golpeou na raiz do penis, dando lugar a grande hemorrhagia. Depois do accidente teve que caminhar meia legua a cavallo, perdendo sempre sangue, até chegar á residencia de seus 
parentes, onde fez um curativo com agua creolinada e pernoitou. Desde a primeira micção depois de ferido sahiu urina pela ferida, com fortes dôres.

Internou-se na Santa Casa de Faxina, onde foi submettido á operação sem resultado, permanecendo a fistula urethro-peniana, a qual motivara a sua entrada na Santa Casa de S. Paulo.

Inspecção - Notamos na linha mediana inferior do penis, no ponto de implantação das bolsas, uma cicatriz de um centimetro mais ou menos, apresentando em seu centro uma fenda alongada, de alguns millimetros de extensão, com bordos de tecido de granulação exuberante á pelle, por onde a.urina se escôava gotejante.

Palpação - Pelo palpar sentimos um endurecimento ao nivel da lesão supra mencionada, dando pela expressão que era dolorosa, sahida de pús pelo orificio da fistula. Durante as micções o doente fazia muito esforço, expellindo sempre antes das primeiras gotas de urina um pouco de pús.

Explorando a urethra verificamos, que ella era permeavel até ao nivel da fistula, ponto em quẹ não conseguimos fazer passar nem uma sonda filiforme, devido ás sinuosidades do estreitamento. Injectámos liquido pelo meato urinario e notámos que o liquido sahia pela fistula.

O catheterismo da fistula para a bexiga tambem não foi possivel, não sómente devido ao diminuto oalibre da urethra, como tambem pelas sensações dolorosas accusadas pelo paciente.

Parece que na lesão primitiva houve secção completa da urethra e que a primeira sutura não deu resultado, formando-se então um técido cicatricical em torno da urethrorrhaphia, dando como consequencia as lesọ̃es que acabamos de assignalar.

Operação - Praticámos a nossa operação de restauração das vias urinarias em dois tempos:

1. ${ }^{\circ}$ tempo - Após rachistovainisação, (0,06 de stovaina), procedemos a derivação vesical da urina por meio de uma cystostomia, para deixarmos a urethra em melhores condições de asepsia, isto é, até que desapparecesse o pús da fistula. Durante quinze dias o doente ficou sob os cuidados do estudante La Terza, o qual solicitamente praticava diariamente irrigações urethraes e da fistula, com soluto de pxycyanureto de mercurio a 1 p. 4.000 .

2. tempo - Achando-se a fistula urethral isenta de suppuração, submettemos o paciente á segunda intervenção sob anesthesia rectal pelo ether-oleo, segundo a technica indicada pelo nosso distincto collega e amigo dr. Pereira Gomes (120,0 de ether misturado a 80,0 de oleo de olivas), e com o auxilio dos drs. D. Define e F. Bayma.

Neste nosso caso não fizemos a urethrorrhaphia em acto continuo á derivação de urina, porque o estado de suppuração em que se achavam as lesões da urethra, diminuiam as probabilidades de exito. 


\section{Z. AMARAL - "Urethrorrhaphia circular".}

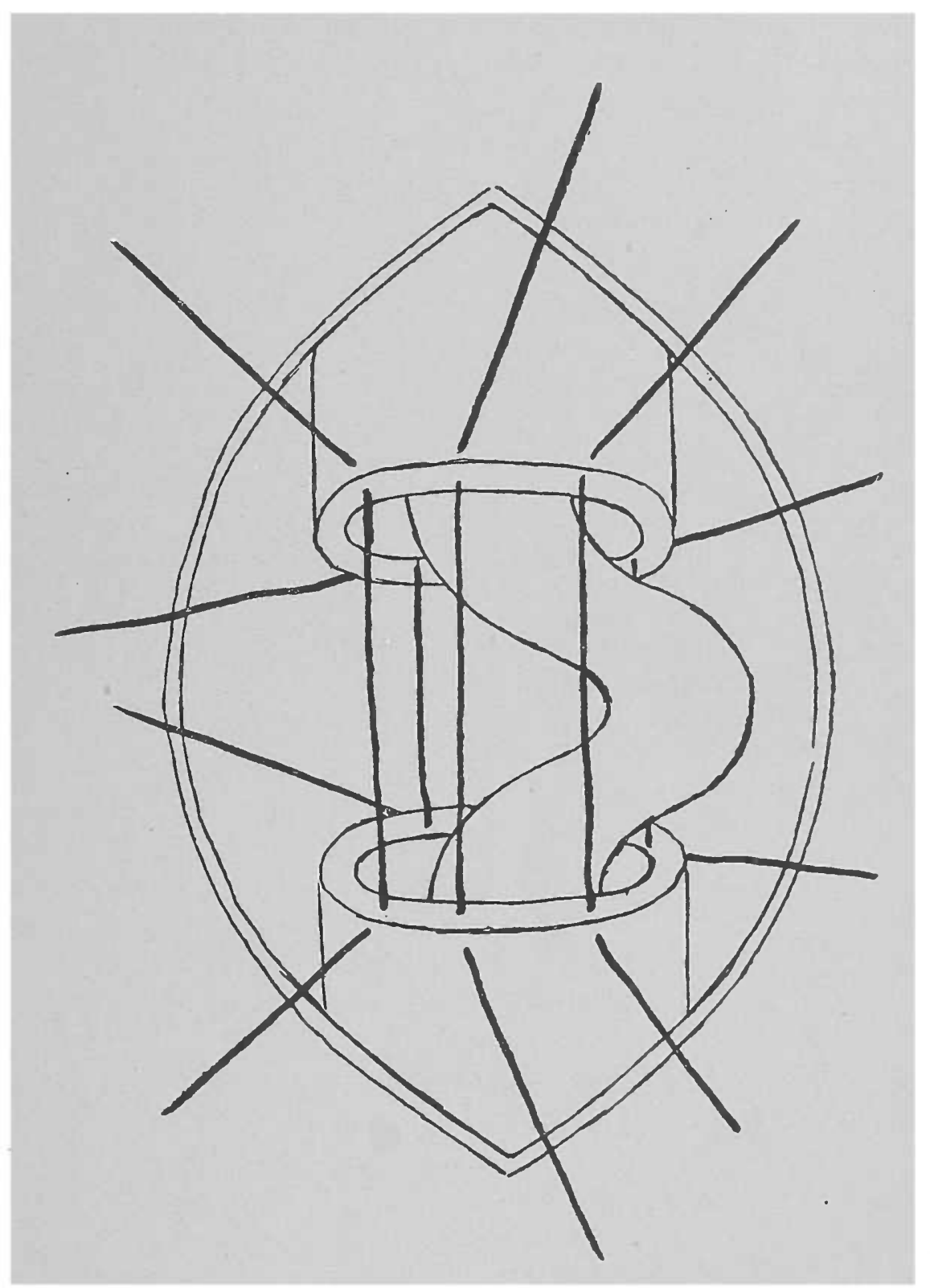

Figura eschematica mostrando como deve ser praticada a sutura da urethra. 

Incisámos a pelle na extensão de uns tres centimetros, na linha mediana inferior, interessando a raiz do penis e as bolsas. Dissecção cuidadosa da urethra e resecção desta na extensão de um centimetro mais ou menos, :bem como dos tecidos periurethraes esclerosados; libertação das duas extremidades da urethra até obtenção de sua perfeita coaptação, sem produzir distensão da mesma. Passámos uma sonda de Nelaton n. $^{\circ} 18$ do meato urinario á bexiga, a qual foi puxada para fóra ao nivel da resecção até formar uma alça que permittisse a sutura da parede superior da urethra em seguida reduzimos a alça formada pela sonda e terminamos a sutura circular, em pontos separados a cat-gut fino.

E' mistér frisarmos que os pontos de sutura não devem atravessar todas as camadas da urethra: a mucosa deverá, quanto possivel, ser respeitada, de modo que os nós fiquem para fóra do canal. $E^{\prime}$ um processo analogo ao que empregamos na cura radical das fistulas vesicovaginaes, tão frequentes nas mulheres, em consequencia a partos laboriosos, e nas sutura's' de bexigas não infeccionadas após talha hypogastrica.

Terminada a sutura circular da urethra, demos ainda a fio de catgut, alguns pontos separados unindo os tecidos circumvisinhos. Terminámmos a operação pela sutura da pelle a crina de Florença, sem drenagem, visto termos tido o maior cuidado na hemostasia.

Periodo post-operatorio - A ferida esteve durante os oito primeiros dias protegida por penso secco e aseptico, o qual, foi mudado por varias vezes. A retirada dos pontos foi feita no nono dia.

Nada de sondagens, nem de lavagens urethraes durante esse tempo. A derivação vesical funccionou, sempre bem, e do decimo dia em diante, o paciente começou a verter agúa pelo canal natural, momento em que retiramos a sonda vesical por onde se fazia a derivação da urina. Do duodecimo dia em diante, iniciamos as dilatações urethraes por meio de vélas, a partir do n. 16 até chegarmos ao n. 23, occasião em que o operado pediu alta, com a ferida vesical tambem cicatrisada, mesmo sem o auxilio de sonda urethral de demóra.

Para terminarmos esta nossa observação, chegamos ás seguintes conclusões:

1. $^{-}$- A sutura da urethra é uma operação geralmente facil, mas de resultado duvidoso.

2. - - Graças á operação complementar de derivação da urina, tornou-se uma intervenção um pouco mais complicada, porém de resultados muito mais seguros.

3. - Devemos geralmente preferir a cystostomia á urethrostomia como meio mais expedito da derivação da urina. 